DOI: https://doi.org/10.24867/04AM99Nikolic

\title{
PROJEKTOVANJE TEHNOLOGIJE TERMIČKE OBRADE LEŽAJNOG PRSTENA PRIMENOM RAČUNARA
}

\section{DESIGN OF THE HEAT TREATMENT TECHNOLOGY OF A BEARING RING USING A COMPUTER}

\author{
Novica Nikolić, Fakultet tehničkih nauka, Novi Sad
}

\section{Oblast- MAŠINSTVO}

Kratak sadržaj - U radu je objašnjena tehnologija termičke obrade prstena kugličnih ležaja. Data je analiza procesa kaljenja $i$ otpuštanja, kao i problemi koji se mogu javiti pri radu. Definisan je pogon termičke obrade FKL-a i spisak potrebnih peći za termičku obradu. Prikazana je upotreba programskog paketa MESAVIS za zadavanje $i$ praćenje parametara procesa termičke obrade putemračunara.

Ključne reči: Tehnologija termičke obrade, leažajni prsten, MESAVIS.

Abstract - In this paper heat treatment tehnology of bearing rings is explained. An analysis of the hardening and tempering process is given, as well as problems that can arise during work. The FKL plant and list of necessary furnaces for heat treatment are defined. The use of the software package MESAVIS for setting and monitoring the parameters of heat treatment process through the computer is shown.

Keywords: Heat treatment tecnology, bearing rings, MESAVIS.

\section{UVOD}

Ležajevi su mašinski elementi čija se osnovna funkcija sastoji u obezbeđivanju uslova za relativno kretanje obrtnih delova i za prenošenje opterećenja između njih.Zbog prirode opterećenja, ležajevi su izloženi habanju, jer se kotrljajna tela kreću po stazama između unutrašnjeg i spoljašnjeg prstena. Zbog toga je neophodno uraditi termičku obradu, koja doprinosti povećanju mehaničkih karakteristika i otpornosti na habanje. Najvažniji zahtevi koje treba da ispuni čelik za ležajeve jesu visoka čvrstoća, otpornost na habanje kotrljanjem i trajna stabilnost dimenzija i oblika.

\section{TEHNOLOGIJA TERMIČKE OBRADE I FAZNE TRANSFORMACIJE}

Termička obrada se može definisiati kao operacija, ili skup operacija koje uključuju zagrevanje, držanje na određenoj temperaturi i potom hlađenje, u cilji dobijanja materijala koji će imati željene osobine, ili koji će biti doveden u željeno stanje za dalju obradu.

\section{NAPOMENA:}

Ovaj rad proistekao je iz master rada čiji mentor je bio dr Branko Škorić, red.prof.
Najznačajnije fazne promene su one koje se odigravaju kao rezultat smanjenja temperature, na kojoj se metal nalazi u ravnotežnom stanju kao jedna faza, na drugu temperaturu na kojoj se stabilno stanje sastoji od neke druge faze ili od dve različite faze. Nastanak prve male pločice cementita je uslovljen difuzijom ugljenika iz neposredne okoline pločice, jer se koncentracija ugljenika u pločici mora uvećati sa $0,8 \% \mathrm{C}$ na $6,67 \% \mathrm{C}$, koliko je potrebno za obrazovanje cementita. Beinitna transformacija. Ako je brzina hlađenja pri kontinualnom hlađenju podešena tako da se transformacija dešava između $200{ }^{\circ} \mathrm{C}$ i $450{ }^{\circ} \mathrm{C}$ ili ako se izotermalno transformiše u ovom opsegu temperatura, nastaće beinitna struktura. Martenzitna transformacija. Ako se hlađenje austenita obavi dovoljno velikom brzinom, ili na dovoljno niskoj temperaturi procesom transformacije nastaće martenzit. Sigurno je samo da je proces transformacije bez difuzije.

\section{KOTRLJAJUĆI LEŽAJEVI}

Ležajevi su mašinski elementi koji služe za smanjenje trenja u ležištima osovine.Oni su oslonci vratila i obrtnih osovina, primaju radijalne $\mathrm{i}$ aksijalne sile koje deluju $\mathrm{i}$ zadržavaju zadati položaj ose obrtanja vratila odnosno osovine.Ležajevi prenose samo sile a ne i obrtne momente. Relativni koeficijent trenja kotrljanja je mali i veoma je blizak koeficijentu tečnog trenja, koji iznosi 0,0015 0,006 .

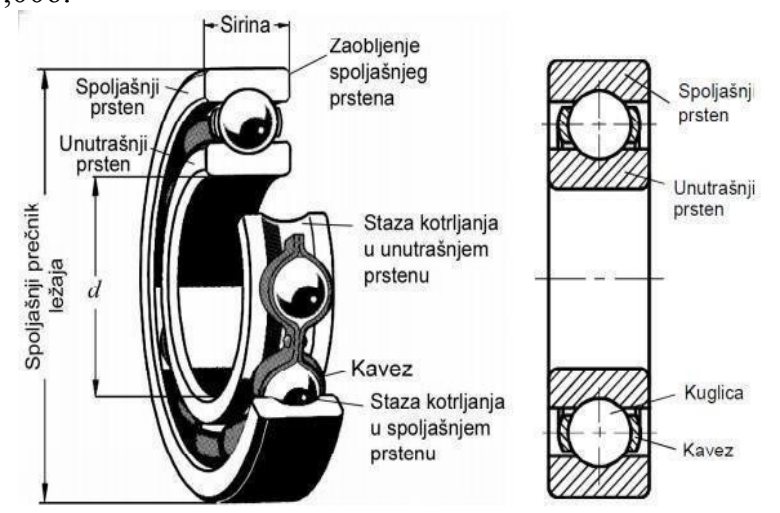

Slika 1. Delovi kotrljajnog ležaja [1]

\section{TEHNOLOGIJA TERMIČKE OBRADE PRSTENOVA LEŽAJA}

Zbog habanja između prstenova i kuglica ležaja, mora se odraditi odgovarajuća termička obrada. Prstenovima ležajnog čelika koji se koriste u FKL se termičkom obradom dobija tvrdoća od 57-62 HRC. Čelici za kotrljajuće ležajeve su po svojoj nameni konstrukcioni, ali 
po sastavu, termičkoj obradi i najvažnijim osobinama zapravo alatni čelici. Najvažniji zahtevi koje treba da ispuni čelik za ležajeve jesu visoka čvrstoća, otpornost na habanje kotrljanjem i trajna stabilnost dimenzija i oblika. Jedan od osnovnih parametara kaljenja je temperatura kaljenja, čije su granice određene greškama u strukturi, koje će se javiti posle kaljenja.

Suviše visoka temperatura ima za posledicu gruboigličasti martenzit i nepovoljno utiče na krupnoću zrna, dok suviše niska temperatura omogućava prisustvo beinita $\mathrm{i}$ grubih karbida u strukturi, te smanjuje tvrdoću. Brzina zagrevanja čelika za kotrljajuće ležajeve na temperaturu kaljenja može biti nešto veća. Kaljenje se vrši u komornim ili protočnim pećima. Najveća količina dispergovanih karbida rastapa se za kratko vreme, nakon što se postigne temperatura kaljenja.

Za kotrljajuće ležajeve, koji moraju imati relativno visoku tvrdoću, temperatura otpuštanja iznosi od $150{ }^{\circ} \mathrm{C}$ do 180 ${ }^{\circ} \mathrm{C}$. Kod otpuštanja natoj temperaturi dolazi do sniženja tvrdoće za 1 do 2 HRC. Ležajni čelik koji se koristi za proizvodnju ležajeva FKL-a - Č.4146 (100Cr6) komercijalne oznake OCR 4 spada u nadeutektoidne čelike sa sadržajem ugljenika preko $0,8 \%$. Duboko hlađenje je veoma značajan proces termičke obrade $u$ industriji ležajeva, jer se ovom metodom količina zaostalog austenita svodi nanajmanju moguću meru. Ovim postupkom se postiže odgovarajuće povećanje tvrdoće i bolja stabilizacija strukture, smanjuju se unutrašnji strukturni naponi i time umanjuje sklonost ka spontanoj promeni specifične zapremine utoku vremena - tzv. starenje.

\section{PEĆI ZA TERMIČKU OBRADU}

Najvažnija namena peći za termičku obradu je osiguravanje ravnomernog zagrevanja komada. Njihova konstrukcija mora odgovarati svim zahtevima standandarda kvaliteta. Postrojenje komornih peći je izvedeno kao niz komornih peći ispred kojih su, ispod kote nula, smeštene kade za kaljenje u ulju.Ispred komornih peći postoji transporter koji omogućava prenos obrađenog materijala. Protočna peć za termičku obradu je sastavljena iz osnovnih tehnoloških jedinica koje su međusobno povezane transportnim i programskim sistemom koji omogućava unapred programiran automatski rad. Postoje dve osnovne jedinice protočne peći u FKL: peć za kaljenje i peć za otpuštanje.

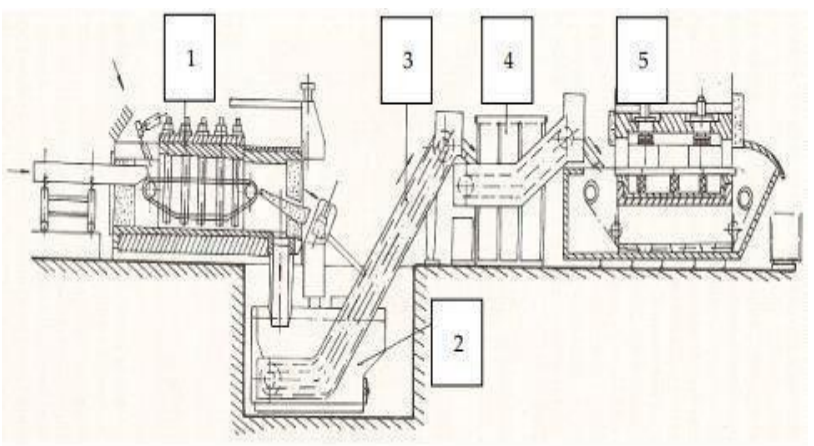

Slika 2.šema protočne peći: 14. - peć za kaljenje, 2- kada za kaljenje u ulju, 3- lift, 4- mašina za pranje, 5-peć za otpuštanje

Prstenovi ležajnog čelika imaju bolje mehaničke karakteristike ukoliko se njihova termička obrada vrši u protočnim pećima a ne u komornim. Razlog tome je postepeno zagrevanje u zonama - tri zone kaljenja i četiri zone otpuštanja.

\section{TERMIČKA OBRADA SPOLJAŠNJEG PRSTENA UH 210N-3/1}

Radi dobijanja potrebne tvrdoće, radi se termička obrada i spoljašnjih i unutrašnjih prstenova. Termička obrada se sastoji od kaljenja i otpuštanja. Struktura čelika se, posle kaljenja, sastoji iz martenzita i zaostalog austenita. Kaljenje podrazumeva proces termičke obrade čelika u kome se komad zagreva iznad temperature A3, a zatim dovoljno brzo hladi kako bi se dobila neravnotežna struktura martenzita velike tvrdoće. Kaljenje se vrši na temperaturi od $840^{\circ} \mathrm{C}$.

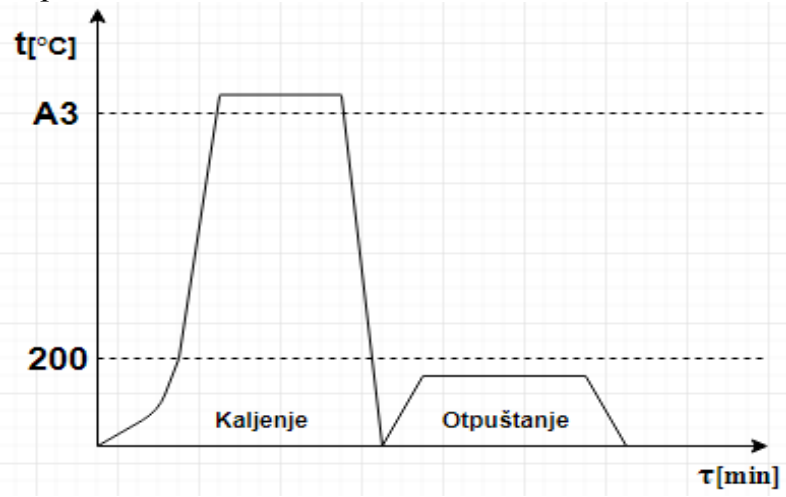

Slika 3. Dijagram termičke obrade ležajnog prstena

Pošto su ove faze nestabilne, postoji prirodna težnja da pređu u stabilniji oblik sa nižim energetskim nivoom. Kod delova ležajeva posle kaljenja, vrši se samo nisko otpuštanje, sa povećanjem žilavosti i uklanjanjem zaostalog austenita.

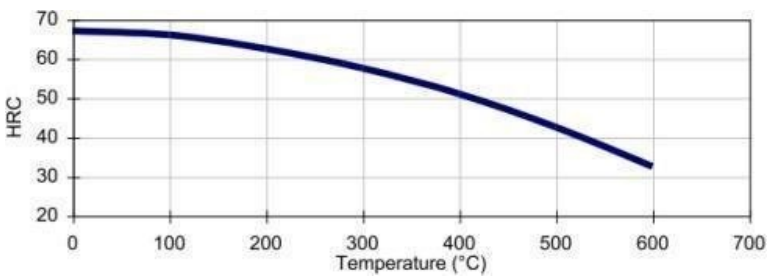

Slika 4. Zavisnost tvrdoće od temperature otpuštanja

Tehnološki, ovalnost je rezultat nesimetrične raspodele unutrašnjih napona pre kaljenja i nejednakog zagrevanja i hlađenja. Ovalnost je određena vrsta kružnog odstupanja. Ovalnost se proverava nakon i pre procesa termičke obrade. [2] Za merenje se koristi specijalni mikrometar čija je šema prikazana na slici 5 .

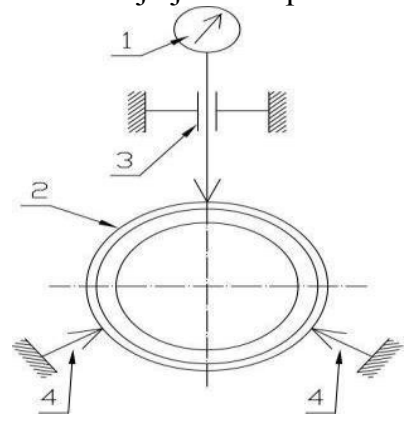

Slika 5. Šema uređaja za merenje ovalnosti

Merena je ovalnost tri prstena, i pravljeni su zapisi nakon svake rotacije za $10^{\circ}$. Rezultati su očitavani sa mernog sata. Ukoliko je odstupanje veće od $0.2 \mathrm{~mm}$, prsten nije 
dobar i ide na doradnu operaciju španovanja, a ukoliko i tada bude preveliko odstupanje, prsten se smatra škartom. Nije prošao kriterijum kvaliteta i neće se slati na dalju obradu brušenja staza.

Veliko odstupanje ovalnosti može biti posledica nejednakog zagrevanja ili hlađenja u toku procesa termičke obrade. Ovalnost je merena na tri unutrašnja prstena uzeta nasumično iz različitih serija. Prsten A pokazuje zadovoljavajuću ovalnost do $0.2 \mathrm{~mm}$. Prsten B ima ovalnost preko $0.2 \mathrm{~mm}$, tako da nije pogodan za dalju mašinsku obradu. Najniža ovalnost je kod prstena C. Za prsten B je neophodno identifikovati uzrok tako velikog odstupanja [3].

\begin{tabular}{|c|c|c|c|c|c|c|c|c|c|c|c|c|c|c|}
\hline \multicolumn{3}{|c|}{ ROTACIJA PRSTENA } & & & & & & 0 & 50 & 60 & & & 90 & 100 \\
\hline \multirow{3}{*}{$\begin{array}{l}\text { REZULTAT } \\
\text { OVALNOST }\end{array}$} & \multicolumn{2}{|c|}{ Prsten $A$} & & & 0.04 & 0.09 & 13 & 0.16 & 0.17 & 0.17 & 0.18 & 19 & 0.2 & 0.19 \\
\hline & \multicolumn{2}{|c|}{ Prsten B } & 3 & & 0.2 & 0.19 & 0.18 & 0.17 & 0.16 & 0.13 & .09 & 1.04 & .03 & 0.03 \\
\hline & & Irsten & 0. & \begin{tabular}{l|l}
.09 & 1 \\
\end{tabular} & 0.05 & 0.02 & & 0.02 & 0.04 & 0.08 & 0.09 & & & 0.1 \\
\hline \multicolumn{15}{|c|}{ Slika 6. Odstupanje ovalnosti prstena $-1[2]$} \\
\hline 110 & & & & 140 & 150 & 160 & 17 & 180 & 80 & 190 & 200 & 210 & 22 & 230 \\
\hline 0.18 & & & & 0.16 & 0.13 & 0.09 & 00 & 0.02 & \begin{tabular}{l|l}
.02 & 0.0 \\
.0
\end{tabular} & .03 & 0.04 & 0.09 & 013 & 0.1 \\
\hline 0.04 & 00 & & & 0.16 & 0.17 & 0.18 & 01 & 01 & 0 & 0.2 & 0.19 & 0.18 & 017 & 0.1 \\
\hline 0.1 & 0.1 & 0. & & 0.15 & 0.14 & 0.1 & 01 & 01 & 11 & 1 & 0.09 & 0.05 & 0,00 & 0.0 \\
\hline \multicolumn{15}{|c|}{ Slika 7. Odstupanje ovalnosti prstena -2 [2] } \\
\hline $2+V$ & & 260 & & & 280 & 290 & 300 & 310 & 320 & 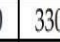 & 34 & 40 & 350 & 360 \\
\hline & 0.17 & 0.18 & & & 0.2 & 0.19 & 0.18 & 0.17 & 0.17 & 0.1 & 0. & 13 & 0.09 & 0.05 \\
\hline & 0.13 & 0.09 & 0.04 & & 0.02 & 0.04 & 0.09 & 0.13 & 0.16 & 0.18 & 0. & & 0.2 & 0.21 \\
\hline & 0.1 & 0.1 & 0.1 & & 0.12 & 0.13 & 0.14 & 0.15 & 0.15 & 0.1 & & 13 & 0.12 & 0.1 \\
\hline
\end{tabular}

Slika 8. Odstupanje ovalnosti prstena -3 [2]

Deformacija materijala i ovalnost prstenova su izazvane zaostalim naponima mašinske obrade i u procesu termičke obrade. Deformacije mogu biti izazvane pogrešnim štelovanjem ili nepoštovanjem tehnoloških instrukcija. Ovalnost se definiše kao razlika dijametera rotiranih za $90^{\circ}[3]$.

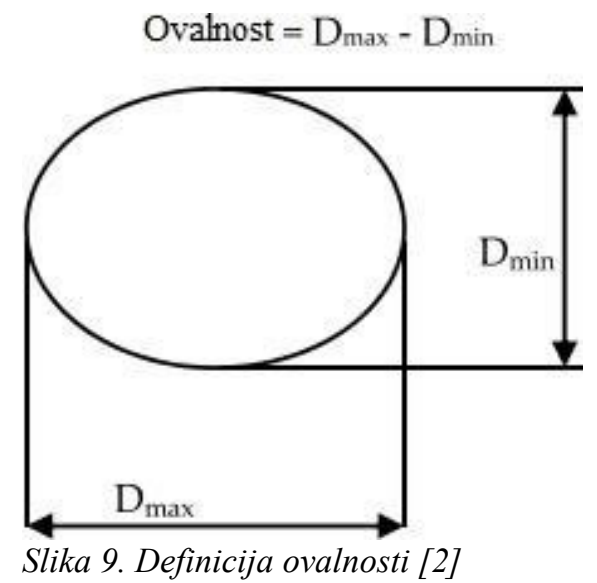

Ovalnost se najčešće povećava nakon procesa termičke obrade. Prikaz merenja jednog prstena pre i nakon termičke obrade prikazan je na slici 10 .

Veliki problem kod delova kotrljajućih ležajeva i preciznih alata je deformisanje za vreme kaljenja, što je posledica zaostalih napona nastalih transformacijom, neravnomernim hlađenjem ili eventualnom pogrešnom manipulacijom komada za vreme hlađenja. Posledice ovih napona se javljaju u dva vida: kao promena oblika i kao promena dimenzija.

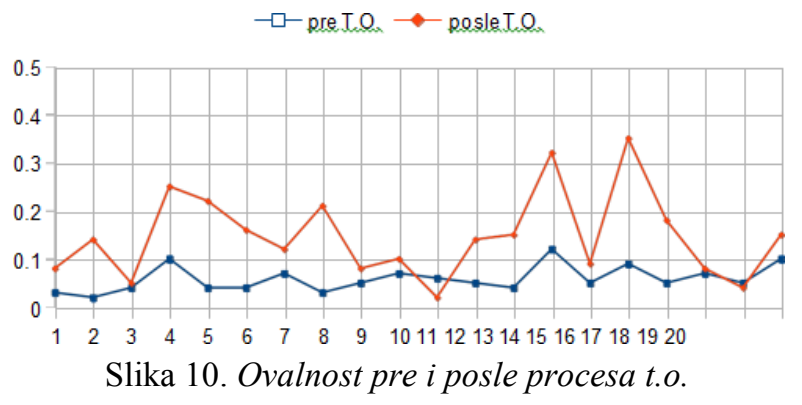

\section{PRIKAZ PROGRAMSKOG PEKETA MESAVIS ZA UNUTRAŠNJI PRSTEN UH 210N-3/1}

10/19/2018

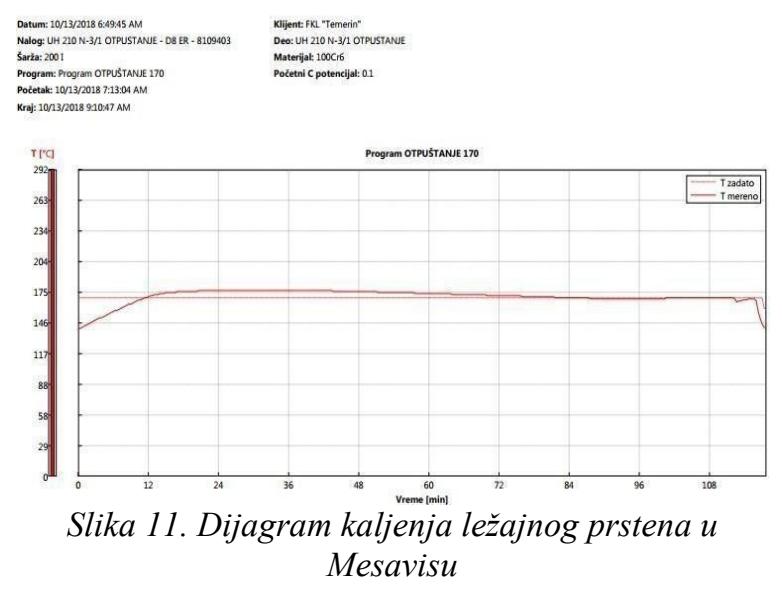

Za spoljašnji prsten UH $210 \mathrm{~N}-3 / 1$, za koji je ranije obrađena problematika termičke obrade, urađeno je softversko zadavanje parametara procesa. Podaci koje dobijamo ovakvim radom se očitavaju na dijagramu, koji predstavlja izlazni rezultat nakon završetka procesa termičke obrade. Iznad dijagrama se nalaze sledeći podaci: Datum i vreme početka i kraja procesa, broj radnog naloga, broj komada u šarži, program koji se koristio, naziv radnog komada, materijal komada i početni $\mathrm{C}$ potencijal. Ovo su opšti podaci, bitni za razlikovanje i kasniju analizu završenihprocesa.

Temperatura atmosfere: Zadata temperatura atmosfere je $840{ }^{\circ} \mathrm{C}$, što je standard kod ležajnih čelika Č.4146. Nakon ubacivanja šarže u peć temperatura je bila nešto niža, i na dijagramu se vidi kako ona postepeno raste dok ne dođe do zadate vrednosti. Na kraju dijagrama uočava pad temperature, to je trenutak otvaranja peći nakon završenog procesakaljenja.

Temperatura ulja: Zadata temperatura ulja je $60{ }^{\circ} \mathrm{C}$, ta temperatura je bila i izmerena $u$ toku celog procesa, sve dok platforma sa zagrejanim komadima nije spuštena $u$ kadu sa uljem, kada je očitan skok temperature ulja. Nakon toga dolazi do paljenja sistema za hlađenje kade sa uljem, pa se vidi i postepeni pad temperature.

$\mathrm{C}$ potencijal: Zadati $\mathrm{C}$ potencijal za ovaj proces je $0,1 \%$. $\mathrm{Na}$ početku procesa očitan je C potencijal $0,2 \%$ jer su se prednja vrata peći otvarala zbog ubacivanja šarže. Nakon toga sledi pad vrednosti zasićenosti atmosfere ugljenikom do zadatih $0,1 \%$. Na kraju sledi ponovni rast $\mathrm{C}$ potencijala, kada se otvaraju zadnja vrata $i$ šarža vadi iz peći. 
Vreme programa 3 (10 min) će krenuti tek nakon što se ostvare svi uslovi za proces, a to je da temperatura atmosfere bude $840{ }^{\circ} \mathrm{C}$ (uz zadatu toleranciju $5{ }^{\circ} \mathrm{C}$ ) a vrednost $\mathrm{C}$ potencijala bude $0,1 \%$ (uz toleranciju $0.03 \%$ ).

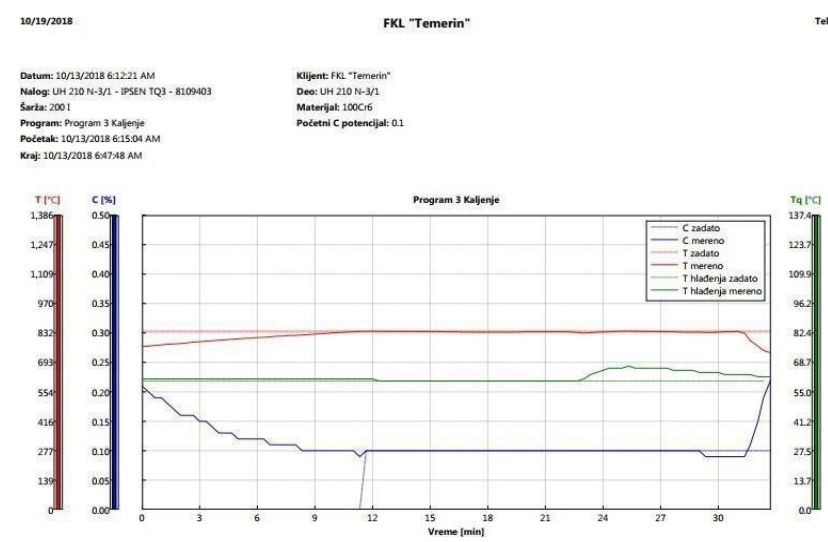

Slika 12. Dijagram otpuštanja ležajnog prstena $u$ MESAVISU

Kod procesa otpuštanja, dijagram je znatno jednostavniji. Opšti podaci su, kao i kod procesa kaljenja, prikazani iznad dijagrama.Na dijagramu otpuštanja očitava se vrednost temperature $\mathrm{u}$ toku vremena. Zadata temperatura otpuštanja za spoljašnji prsten UH $210 \mathrm{~N}-3 / 1$ je $175^{\circ} \mathrm{C}$, ali se u programu $170{ }^{\circ} \mathrm{C}$. Razlog tome su mikroprekidači u peći za otpuštanje D8 ER, koji se ne isključe na vreme grejače tako da ima malog "prebačaja" temperature. To ne predstavlja ozbiljan problem jer se temperatura zadržava u granicama tolerancija.

Prednosti softverskog zadavanja i praćenja parametara termičke obrade su prvenstveno u dobijanju dodatne stabilnosti procesa. Ukoliko neki od parametara proesa nije u graničnim vrednostima, odmah se analizira razlog tome. Ako vrednosti koje odstupaju nisu znatno uticajne na kvalitet obrađenih komada, rad u pećima se nastavlja i istovremeno se radi na rešavanju problema.

Kada su vrednosti znatno van granica tolerancije parametara u pećima, rad se zaustavlja i hitno vrši popravka peći. Kvar peći je najčešći uzrok loših parametara procesa. Ukoliko se desi na merenju tvrdoće nakon procesa termičke obrade, da neki komadi nemaju dovoljnu tvrdoću, ulazi se u bazu podataka završenih radnih naloga Mesavisa, kako bi se našao uzrok problema.

\section{ZAKLJUČAK}

Zbog prirode opterećenja, ležajevi su izloženi habanju, jer se kotrljajna tela kreću po stazama između unutrašnjeg i spoljašnjeg prstena. Termičkom obradom spoljašnjeg prstena UH $210-\mathrm{N}-3 / 1$ postižu se potrebne mehaničke karakteristike. Kaljenje je vršeno na $840{ }^{\circ} \mathrm{C}$ sa zadržavanjem na toj temperaturi 10 minuta, uz $\mathrm{C}$ potencijal 0,1 . Otpuštanjem na $175{ }^{\circ} \mathrm{C}$ dobijaju se završne vrednosti tvrdoće i relaksacija strukture. Radi dodatne sigurnosti procesa i zahteva tržišta, uvedena je i kontrola postupaka termičke obrade putem računara.

Programski paket Mesavis omogućava zadavanje i praćenje parametara procesa termičke obrade. Izlazni zapisi su dijagrami sa kojih se očitava promena temperature atmosfere i ulja, zatim $\mathrm{C}$ potencijal u toku vremena. Ovi podaci se analiziraju i pružaju dodatnu sigurnost $u$ stabilnost procesa.

Na ovaj način se mogu na vreme otkriti greške unutar peći za termičku obradu i pronaći uzroci njihovog nastanka.

\section{LITERATURA}

[1] Ilija Pantelić, 'Tehnologija termičke obrade čelika', Subotica 1976

[2] Vladimir M. Blanuša, ',Analiza cilindrično valjkastih ležaja za specijalne namene', Fakultet tehničkih nauka, Novi Sad, 2017

[3] J. Burke, ' Kinetika faznih transformacija u metalima', Ujedinjeno Kraljevstvo, 1981

\section{Kratka biografija:}

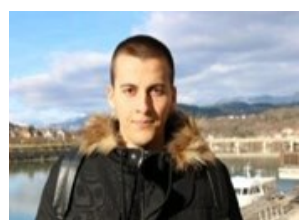

Novica Nikolić je rođen u Bijeljini 1994.god. Diplomski-master rad na Fakultetu tehničkih nauka u Novom Sadu iz oblasti tehnologije termičke obrade odbranio je 2018.god.

Dr Branko Škorić, redovni profesor na Fakultetu tehničkih nauka u Novom Sadu, rođen 1955. god. Doktorirao iz oblasti inženjerstva površina i nanotehnologija. 